\title{
A Despesa Primária do Governo Central: estimativas e determinantes no período $1986-2016$ *
}

\author{
Manoel Pires ${ }^{1}$ \\ Bráulio Borges ${ }^{2}$
}

\section{Resumo}

O crescimento das despesas primárias do Governo Central durante o processo de democratização é um fato normalmente atribuído à Constituição Federal de 1988. Este artigo apresenta novas estimativas para a despesa primária desde 1986 e decompõe seu crescimento considerando fatores relacionados ou não à Constituição. Os resultados mostram que considerando apenas os efeitos Constitucionais, a despesa primária teria se mantido estabilizada no período.

\section{Palavras-Chave}

Despesas primárias. Constituição Federal. Seguridade Social.

\begin{abstract}
Federal Government primary expenditures growth in Brazil during the process of democratization has been assigned mainly to 1988 Federal Constitution. This paper presents new estimations of primary expenditure beginning in 1986 and presents growth decomposition between Constitutional and non-Constitutional factors. The results show that expenditures would have been stable without the non-Constitutional factors that created new financial obligations.
\end{abstract}

\section{Keywords}

Primary expenditures. Federal Constitution. Social Security.

\section{JEL Classification}

H53. H12. O11.

- Agradecemos os comentários e sugestões recebidos em seminários realizados no IBRE/FGV. No entanto, erros e omissões são de responsabilidade dos autores.

1 Pesquisador - Instituto Brasileiro de Economia - Fundação Getúlio Vargas (IBRE-FGV) Endereço: Rua Barão de Itambi, 60 - Botafogo - Rio de Janeiro/RJ - Brasil - CEP: 22231-000. E-mail: manoel.pires@fgv.br - ORCiD: https://orcid.org/0000-0002-1914-2004.

2 Pesquisador - Instituto Brasileiro de Economia - Fundação Getúlio Vargas (IBRE-FGV) Endereço: Rua Barão de Itambi, 60 - Botafogo - Rio de Janeiro/RJ - Brasil - CEP: 22231-000. E-mail: braulioborges@hotmail.com - ORCiD: https://orcid.org/0000-0002-5625-7206. Recebido: 31/10/2017. Aceite: 15/10/2018. 


\section{Introdução}

O desafio fiscal brasileiro no momento atual é enorme. O aumento expressivo do déficit primário do governo federal nos últimos anos e a necessidade de se estabilizar a dívida pública (tanto a bruta como a líquida) intensificou o debate sobre a melhor forma de se obter o equilíbrio fiscal. ${ }^{1}$ Pelo lado da despesa, esse debate ganhou materialidade a partir do PLP 257/2016 que propôs a instituição de um limite de crescimento para a despesa primária. Posteriormente, o Governo Federal aprovou a Emenda Constitucional 95/2016, que indexou praticamente todo o gasto primário do governo central à taxa de inflação passada. ${ }^{2}$

A concentração do debate do ajuste fiscal em torno da despesa primária tem duas justificativas principais. A primeira é que a carga tributária brasileira já é bastante elevada, considerando o estágio de desenvolvimento econômico do Brasil e, portanto, o ajuste pela receita - solução colocada em prática no final dos anos 1990 e nos anos 1960 - é percebida, em geral, como uma solução com custo elevado. ${ }^{3}$ A segunda justificativa reside no fato de que a despesa primária federal, em percentual do PIB, vem em trajetória de contínua elevação a partir da nova institucionalidade estabelecida pela Constituição Federal de $1988 .^{4}$

Esse movimento da despesa apresenta dois problemas. Em primeiro lugar, essa situação não representa um equilíbrio macroeconômico: nenhuma despesa deve crescer indefinidamente como proporção do PIB. Em segundo lugar, ela coloca uma pressão altista na carga tributária. Em uma versão extremada dessa lógica, não seria possível aumentar a carga tributária para financiar um gasto que cresce indefinidamente.

1 O resultado primário do setor público consolidado não financeiro passou de um saldo positivo equivalente a 1,7\% do PIB, em 2013, para um déficit correspondente a 2,5\% do PIB, em 2016. A dívida bruta do governo geral, por sua vez, subiu de 51,5\% do PIB, em 2013, para 69,9\% do PIB, em 2016. Trajetória semelhante é observada na dívida líquida.

2 Esse debate gerou outras propostas, como a definição de limites para a dívida pública a partir do PRS 84/2007. Para uma avaliação dos efeitos e das vantagens de cada tipo de regra fiscal, ver Schaechter et al. (2012). Para a experiência norte-americana com limites para a dívida pública, ver Austin (2015).

3 Segundo estudo da Receita Federal do Brasil (2015), a carga tributária do Brasil equivaleu a 32,4\% do PIB naquele ano, próxima daquela observada em países como a Nova Zelândia (32,4\% do PIB) e o Reino Unido (32,6\% do PIB) e bem acima daquelas observadas em países como o Chile (19,8\% do PIB) e a Coreia do Sul (24,5\% do PIB).

4 Rezende, Araújo \& Oliveira (2006) descrevem um movimento em que o aumento da tributação no Brasil gera, por meio das vinculações orçamentárias, aumentos automáticos das despesas. O excesso de vinculações seria uma razão para esse processo. A outra razão é o elevado nível de despesas obrigatórias. 
Este artigo irá contribuir com esse debate produzindo novas estimativas da despesa primária federal a partir de 1986. Vale lembrar que os dados oficiais produzidos pela Secretaria do Tesouro Nacional, da forma como são conhecidos hoje, têm início apenas em 1997. Desse modo, o presente trabalho ampliará o período de análise em 12 anos, incorporando informações sobre a política fiscal de três outros mandatos presidenciais: Sarney, Collor e Itamar, além dos anos iniciais do primeiro governo FHC.

A ampliação das séries temporais certamente ajudará a aperfeiçoar o entendimento a respeito do comportamento da política fiscal em vários aspectos, na medida em que elas cobrirão todo o período posterior à promulgação da Constituição Federal de 1988 (CF/88) - um marco importante do debate fiscal, pois são muitos os autores que identificam uma relação clara de causalidade entre esse evento e o crescimento praticamente ininterrupto da despesa pública nas décadas seguintes. Adicionalmente, essa nova base de dados permite avaliar a execução da política fiscal em alguns períodos prévios ao ano de 1997, seu processo de formação e sua relação com os ciclos econômicos.

Nesse sentido, com as novas estatísticas serão realizadas duas aplicações. A primeira refere-se à decomposição das despesas primárias federais e como essa decomposição foi alterada em função de processos cíclicos e estruturais. A segunda aplicação analisará os determinantes não constitucionais e os diretamente relacionados à $\mathrm{CF} / 88$ do crescimento estrutural da despesa com o objetivo de aperfeiçoar o entendimento em torno desse fenômeno.

Vale lembrar que os manuais de finanças públicas tradicionalmente tratam esse período que vai de meados dos anos 80 até a primeira metade da década seguinte de maneira relativamente superficial, apresentando dados nem sempre coerentes e, ainda, gerando descontinuidades nas séries anteriores e posteriores à implementação do Plano Real. ${ }^{5}$

Este artigo está dividido da seguinte maneira. A próxima seção apresentará as principais interpretações sobre a dinâmica da despesa primária no Brasil. A terceira seção apresentará a metodologia de construção dos dados de despesa primária. Na quarta seção é feita uma análise dos resultados, identificando alguns comportamentos da política fiscal ao longo do tempo. A quinta seção mapeará os componentes e decisões não relacionadas à

${ }^{5}$ Ver, por exemplo, Rezende (2001) e Giambiagi \& Além (2008). 
$\mathrm{CF} / 88$ que explicam o crescimento da despesa primária. Por fim, seguem as principais conclusões do artigo.

\section{Interpretações sobre o Crescimento da Despesa Primária no Brasil}

O marco temporal da análise que será feita neste trabalho inicia em 1986, ano de criação da Secretaria do Tesouro Nacional (STN) - dois anos antes da promulgação da $\mathrm{CF} / 88$. Justamente por conta da criação da STN é que está disponível o conjunto de informações necessário - no âmbito da Execução Financeira do Tesouro Nacional - para que sejam elaboradas essas estimativas.

Do ponto de vista econômico, esse período é marcado por uma série de crises de balanço de pagamentos e pela progressiva aceleração da inflação, que foi alvo de diversos planos de estabilização. Um reflexo dessa sequência de crises foi o colapso do Estado desenvolvimentista, que caracterizou o modelo de crescimento das décadas anteriores.

O debate fiscal da época estava relacionado a indicadores de sustentabilidade e de seu impacto sobre a demanda agregada, levando em conta basicamente as informações fiscais no critério "abaixo da linha" (resultado primário e juros reais). ${ }^{6}$ Com a promulgação da $\mathrm{CF} / 88$, foi feita uma opção em direção à construção de um Estado de Bem-Estar Social como alternativa ao antigo Estado desenvolvimentista. A CF/88, portanto, sacramentou a transição entre essas duas formas de organização do Estado.

A CF/88 criou um regime de previdência e assistência social bastante mais inclusivo do que aquele existente até então no Brasil, além da previsão de um sistema universal de saúde. ${ }^{7}$ Além disso, definiu o salário mínimo nacional como o piso previdenciário (cujo poder de compra deveria ser preservado ao longo do tempo) e regrou as principais características de organização do funcionalismo público (como a estabilidade e a irredutibilidade de salários).

6 Ver Giambiagi e Além, (2008).

7 Para uma análise do impacto da expansão dessa rede de proteção social, ver Beltrão, Pinheiro \& Oliveira 2002. 
Outro fenômeno importante na criação de novas despesas dada pela CF/88 é o que Rezende, Oliveira e Araújo (2006) chamam de "efeito cremalheira". Este efeito se dá pela separação entre o orçamento fiscal e o orçamento da seguridade social. O orçamento fiscal é financiado pelos impostos que são repartidos com Estados e Municípios. O orçamento da seguridade social, por sua vez, é financiado pelas contribuições sociais - que não são repartidas, sendo utilizadas para financiar a seguridade social no nível federal.

Nesse contexto, em períodos de ajuste fiscal, o governo federal deu preferência a elevações da carga tributária por meio das contribuições, de modo a não ter que repartir esses recursos com os demais entes da federação. $\mathrm{E}$ ao aumentar as contribuições, o governo federal acaba por criar mais despesas sociais por conta das vinculações e da aplicação dos mínimos constitucionais e da maior disponibilidade no orçamento da seguridade. O "efeito cremalheira" seria esse processo de reprodução das despesas pelo aumento das contribuições sociais.

Outras explicações por trás do processo de crescimento das despesas têm raízes em aspectos políticos e institucionais. Um primeiro aspecto diz respeito ao exercício de influência por parte dos grupos de interesse organizados e de lobbies de setores da sociedade que disputam espaço no orçamento, fenômeno também denominado como conflito distributivo. ${ }^{8}$ Já o segundo paira sobre o fato de que parte relevante dos eleitores, em economias com elevada desigualdade de renda e riqueza, prefere votar em programas que favoreçam programas de distribuição de renda. Como os resultados eleitorais são em grande medida decididos pelo eleitor mediano, isso acaba gerando uma tendência de elevação dos gastos com transferências e com políticas sociais (Persson \& Tabellini 2002). O terceiro elemento está associado ao aumento da fragmentação político-partidária ensejada pela nova Constituição - algo que, em um regime de presidencialismo de coalizão como o brasileiro, acaba gerando uma maior pressão por gastos (Crivelli, Gupta, Mulas-Granados \& Correa-Caro 2016). ${ }^{9}$

8 A referência a essa interpretação ficou conhecida como meia entrada. Um exemplo dessa literatura pode ser encontrado em Bonomo, Brito \& Martins (2015) que estudaram os efeitos dos empréstimos do BNDES. Um resultado prático desse debate é a instituição da Taxa de Longo Prazo (TLP) por meio da Lei 13.476 de 2017.

9 Houve uma tentativa de moderar esse impulso por meio da criação de uma cláusula de barreira em 1995, que teria validade somente dez anos depois. Não obstante, às vésperas da entrada em vigor dessa regra, o Supremo Tribunal Federal julgou como inconstitucional a Lei 9.096/1995, que regulamentava o artigo 17 da CF88. 


\section{Metodologia}

As informações estatísticas sobre a política fiscal foram sendo aperfeiçoadas com o tempo a partir dos trabalhos de aprimoramento metodológico realizados nos vários órgãos de governo. Por conta disso, na medida em que as informações foram sendo melhoradas, foi possível simplificar a metodologia de apuração - razão pela qual ela será apresentada, a seguir, a partir de três marcos metodológicos e históricos distintos.

\subsection{O Período 1986-1989}

O trabalho de consolidação das estatísticas fiscais tem como ponto de partida as séries de execução financeira disponíveis no endereço eletrônico do Banco Central do Brasil, cujo histórico se inicia em 1986. Nessa base de dados estão disponíveis informações das despesas com pessoal, custeio (incluindo despesas com investimento e restos a pagar), outras vinculações e operações oficiais de crédito. ${ }^{10}$

Naquela época, a segregação das contas do Tesouro daquelas da Previdência Social eram mais explícitas do que atualmente. Dessa forma, o que se define como custeio na base de dados do Banco Central não inclui despesas com o sistema de previdência social e não se confunde com o total das despesas correntes que é o conceito usualmente utilizado.

As informações sobre a previdência foram compiladas a partir das séries históricas disponíveis no IPEADATA para o período 1986-1995, que por sua vez tem como fonte o extinto Ministério da Previdência Social. ${ }^{11}$ O Anuário Estatístico da Previdência Social de 2014 (AEPS) disponibiliza essas informações a partir de 1996. A checagem dessas informações mostrou haver bom grau de aproximação nas informações disponibilizadas pelo IPEADATA.

${ }^{10}$ Existem discrepâncias importantes com relação a classificações contábeis, dados financeiros e conceitos. Tentamos minimizar a importância dessas diferenças cruzando o maior número de informações disponíveis. Eventuais discrepâncias não parecem mudar o resultado final de nossas conclusões, em particular quando analisadas em percentual do PIB.

${ }^{11}$ Os dados apresentados pelo IPEADATA divulgam as despesas com os gastos totais do INSS. Dessa rubrica foram excluídas as despesas de caráter administrativo tais como pessoal e dataprev e as despesas relacionadas às políticas assistenciais como o EPU e a LOAS. 
A partir desses dados brutos disponibilizados pelo BCB e pela Previdência Social, é possível realizar alguns aprimoramentos metodológicos para a produção das estimativas consistentes das despesas primárias.

O primeiro aprimoramento metodológico importante é entender o que está contabilizado na rubrica "operações oficiais de crédito". Essa série não possui valores em 1986 e 1987. Em 1987, o Governo Federal editou o Decreto 94.442, que criou o orçamento das operações oficiais de crédito. Somente em 1988 surgiram os primeiros valores na série histórica dessa rubrica.

Além disso, o Decreto supracitado classifica como operações oficiais de crédito todas as despesas primárias e financeiras relacionadas ao crédito público. Com isso, essa rubrica registrou um valor equivalente a 5,8\% do PIB no primeiro ano de sua existência, recuando rapidamente nos anos seguintes, para abaixo de 1\% do PIB $^{12}$ no início dos anos 1990.

Como essa mistura entre dados primários e financeiros não permite uma separação adequada para os propósitos deste trabalho, foi necessário recorrer a informações secundárias. Giambiagi (1997) apresenta dados das despesas das operações de crédito com impacto primário para o custeio agrícola e relacionadas a subsídios ao setor exportador. Assim, os dados das operações de crédito com impacto primário foram obtidos a partir desta fonte secundária, servindo para dimensionar a estimativa de subsídios no orçamento no período anterior a $1997 .{ }^{13}$

A rubrica "outras vinculações" diz respeito às transferências para os fundos públicos. Nesse caso, o FAT é a despesa mais importante. Essa conta foi adicionada à rubrica de despesas de custeio.

O Ministério do Trabalho e Emprego (MTE) divulga informações sobre a despesa com o programa de seguro desemprego desde 1986, quando o programa foi criado. Esses valores foram incorporados nos dados e descontados das despesas com custeio. ${ }^{14}$ No caso das despesas com outros benefícios assistenciais, tais como a Renda Mensal Vitalícia (RMV), foi possível recuperar as informações no AEPS 2014 nas tabelas de número 7.9 e 7.10.

\footnotetext{
${ }^{12}$ Giambiagi \& Barbosa (1995) e Giambiagi (1997) relatam uma série de medidas que produziram a redução dessa despesa.

${ }^{13}$ No caso dos anos de 1986-87, os dados divulgados por Giambiagi \& Barbosa (1995) foram descontados da rubrica de despesas de custeio.

${ }^{14}$ Foram solicitadas ao MTE, por meio da Lei de Acesso à Informação, os valores das despesas com o abono salarial, mas o Ministério não enviou a resposta até o fechamento deste trabalho.
} 
As despesas com Encargos Previdenciários da União (EPU) também foram obtidas no IPEADATA.

As informações disponibilizadas pelo Banco Central do Brasil possuem frequência mensal, ao passo que os dados da previdência e dos subsídios estão disponíveis apenas em bases anuais. Desse modo, este artigo irá se concentrar na análise da dinâmica dos dados anuais. É possível estudar o comportamento de diversos itens específicos das despesas primárias a partir de bases mensais - o que pode ser interessante, por exemplo, no caso da agenda de pesquisa associada à estimação dos multiplicadores fiscais."

\subsection{O Período 1990-1996}

Para o período 1990-1996 foi possível ter acesso aos Relatórios de Execução Financeira do Tesouro Nacional de forma direta. Os dados nesses relatórios são apresentados de forma análoga àquela apresentada pelo Banco Central, tal como discutido na subseção anterior para o período 1986-1989. Desse modo, torna-se possível aferir a qualidade da metodologia que foi empregada até o ano de 1989.

É importante registrar que alguns desafios permanecem, tais como a questão das operações oficiais de crédito com impacto primário, cuja informação continuou sendo obtida a partir de Giambiagi (1997). Os procedimentos aplicados para as despesas com previdência social, benefícios assistenciais e seguro desemprego são os mesmos discutidos anteriormente.

Por fim, é importante assinalar que o Relatório de Execução Financeira não está disponível para o ano de 1994. Para esse ano específico, foi empregada a mesma metodologia utilizada para o período anterior, com alguns ajustes que serão detalhados na apresentação dos resultados (quando será possível comparar as diversas estimativas para o gasto primário).

${ }^{15}$ Ver, por exemplo, Pires (2017). Cahuc \& Carcillo (2012), por sua vez, estudam o comportamento dos salários no setor público durante os episódios de expansões e recessões. 


\subsection{O Período 1997-2016}

Apesar dos dados a partir de 1997 serem mais consistentes, alguns ajustes também são necessários. O primeiro ajuste envolve descontar as despesas registradas com a chamada desoneração da folha, por se tratar de renúncias fiscais. ${ }^{16} \mathrm{O}$ segundo consiste na exclusão da multa adicional do FGTS, na medida em que se trata apenas de um mecanismo contábil de repasse ao Fundo que está fora do orçamento. Ambos os ajustes foram corretamente apontados por Orair \& Gobetti (2016). Já o terceiro está relacionado ao pagamento atípico de passivos ocorrido em dezembro de 2015 - algo que é justificado metodologicamente por conta do objetivo desta pesquisa. Uma possibilidade seria fazer esse ajuste levando em conta a competência em que foi criada a despesa, ${ }^{17}$ o que reforça o interesse na avaliação de seu impacto macroeconômico e também de seu processo de formação, tal como realizado em Orair \& Gobetti (2016).

Outra possibilidade seria simplesmente excluir esse pagamento dos dados observados em dezembro de 2015, classificando-o apenas como um pagamento extraordinário. Nesse caso, o interesse maior estaria nos efeitos estruturais da política fiscal, tal como feito no monitor fiscal da SPE/MF (2016).

Seria possível, ainda, considerar a série tal como disponibilizada pelo Tesouro Nacional, caso o objetivo seja avaliar os condicionantes da dívida pública. Como o foco deste trabalho está na discussão da despesa primária e nos seus determinantes, optou-se pela primeira abordagem. ${ }^{18}$

Por fim, foi excluída a despesa oriunda da capitalização da Petrobrás por meio da operação de cessão onerosa em 2010. A despesa com o FIES, antes classificada como financeira, passou a ser considerada como uma despesa primária a partir de junho de 2017, tendo sido retropolada até 2016. Por questões de comparabilidade temporal, já que o FIES existia muito antes de 2016, essa despesa também foi excluída do cálculo.

\footnotetext{
${ }^{16}$ A contabilidade pública tratou essa renúncia como despesa, pois a legislação determinou que houvesse a compensação ao RGPS.

17 Vale lembrar que, na contabilidade pública brasileira, todos os fluxos primários são apurados pelo critério caixa. Somente os juros apropriados sobre o estoque da dívida são apurados pelo critério competência.

18 Os dados utilizados para este ajuste foram publicados no quadro 44 da Nota para Imprensa de dezembro de 2015 do Banco Central do Brasil, com o histórico se iniciando em dezembro de 2001.
} 


\subsection{Análise Comparada das Estimativas}

A Tabela 1 apresenta uma comparação entre as bases de informações do BCB e da STN para as despesas com pessoal e custeio entre 1990 e 1995 e aquelas apresentadas por Giambiagi \& Além (2008). ${ }^{19}$

Os resultados mostram que aderência dos dados entre a STN e o BCB é praticamente total. A única discrepância está na estimativa para o gasto com custeio em 1995. Essa constatação é importante porque valida a metodologia utilizada na estimativa das despesas primárias para o período 1986-1989.

No caso dos dados publicados por Giambiagi \& Além, parece haver um viés positivo nas despesas com custeio. Assim, a decisão metodológica foi de adotar as despesas com pessoal de Giambiagi \& Além (2008) para 1994 (que é igual à do BCB) e utilizar as despesas de custeio publicadas pelo $\mathrm{BCB}$.

Tabela 1 - Comparações das despesas com pessoal e custeio (\% do PIB)

\begin{tabular}{|r|r|r|r|r|r|r|}
\hline & \multicolumn{2}{|c|}{ STN } & \multicolumn{2}{c|}{ BCB } & \multicolumn{2}{c|}{ Giambiagi e Além } \\
\hline & Pessoal & Custeio* & Pessoal & Custeio* & Pessoal & Custeio* \\
\hline 1990 & $5,0 \%$ & $2,9 \%$ & $5,0 \%$ & $2,9 \%$ & ND & ND \\
\hline 1991 & $3,4 \%$ & $3,5 \%$ & $3,4 \%$ & $3,5 \%$ & ND & ND \\
\hline 1992 & $3,6 \%$ & $2,5 \%$ & $3,6 \%$ & $2,5 \%$ & ND & ND \\
\hline 1993 & $4,2 \%$ & $4,0 \%$ & $4,2 \%$ & $4,0 \%$ & $\mathrm{ND}$ & $\mathrm{ND}$ \\
\hline 1994 & $\mathrm{ND}$ & $\mathrm{ND}$ & $5,1 \%$ & $3,5 \%$ & $5,1 \%$ & $4,0 \%$ \\
\hline 1995 & $5,0 \%$ & $3,0 \%$ & $5,1 \%$ & $3,0 \%$ & $5,1 \%$ & $3,8 \%$ \\
\hline
\end{tabular}

* Acrescido da rubrica "outras vinculações".

Tendo procedido a análise de robustez dos resultados, é importante avaliar o efeito dos ajustes nas despesas primárias em relação à estatística oficial. A Tabela 2 apresenta o resultado da consolidação a partir das estatísticas disponíveis pela Secretaria do Tesouro Nacional. Os ajustes realizados na série entre 1997 e 2016 são módicos em relação aos números oficiais. A discrepância relevante se dá em 2015 e 2016, quando as operações atípicas com subsídios crescem bastante e em nossa proposta são tratadas por competência, no ano de contratação da despesa e não no de seu pagamento. A diferença média no período inteiro é de 0,2 p.p. do PIB. Por outro lado,

${ }^{19}$ No caso da despesa de custeio apresentada na Tabela 1, incluiu-se a rubrica "outras vinculações" sem a exclusão das demais variáveis como o seguro-desemprego, uma vez que o objetivo é apenas comparar a qualidade das informações brutas disponíveis para o trabalho. 
a análise comparativa mostra que o maior ganho da metodologia apresentada está em produzir dados no período 1986-1996 que não estavam disponíveis até então.

Tabela 2 - Comparação das séries de despesa primária (\% do PIB)

\begin{tabular}{|r|r|r|r|}
\hline & Consolidação & STN & Diferença \\
\hline 1986 & $12.7 \%$ & $\mathrm{NA}$ & $\mathrm{NA}$ \\
\hline 1987 & $13.0 \%$ & $\mathrm{NA}$ & $\mathrm{NA}$ \\
\hline 1988 & $12.7 \%$ & $\mathrm{NA}$ & $\mathrm{NA}$ \\
\hline 1989 & $11.9 \%$ & $\mathrm{NA}$ & $\mathrm{NA}$ \\
\hline 1990 & $11.5 \%$ & $\mathrm{NA}$ & $\mathrm{NA}$ \\
\hline 1991 & $10.7 \%$ & $\mathrm{NA}$ & $\mathrm{NA}$ \\
\hline 1992 & $10.6 \%$ & $\mathrm{NA}$ & $\mathrm{NA}$ \\
\hline 1993 & $13.5 \%$ & $\mathrm{NA}$ & $\mathrm{NA}$ \\
\hline 1994 & $14.0 \%$ & $\mathrm{NA}$ & $\mathrm{NA}$ \\
\hline 1995 & $13.1 \%$ & $\mathrm{NA}$ & $\mathrm{NA}$ \\
\hline 1996 & $13.2 \%$ & $\mathrm{NA}$ & $\mathrm{NA}$ \\
\hline 1997 & $14.0 \%$ & $14.0 \%$ & $0.0 \%$ \\
\hline 1998 & $14.8 \%$ & $14.8 \%$ & $0.0 \%$ \\
\hline 1999 & $14.6 \%$ & $14.6 \%$ & $0.0 \%$ \\
\hline 2000 & $14.8 \%$ & $14.8 \%$ & $0.0 \%$ \\
\hline 2001 & $15.6 \%$ & $15.6 \%$ & $0.0 \%$ \\
\hline 2002 & $15.7 \%$ & $15.9 \%$ & $-0.1 \%$ \\
\hline 2003 & $15.0 \%$ & $15.1 \%$ & $-0.1 \%$ \\
\hline 2004 & $15.5 \%$ & $15.6 \%$ & $-0.1 \%$ \\
\hline 2005 & $16.2 \%$ & $16.4 \%$ & $-0.2 \%$ \\
\hline 2006 & $16.6 \%$ & $16.8 \%$ & $-0.1 \%$ \\
\hline 2007 & $16.8 \%$ & $16.9 \%$ & $-0.1 \%$ \\
\hline 2008 & $16.1 \%$ & $16.2 \%$ & $0.0 \%$ \\
\hline 2009 & $17.4 \%$ & $17.4 \%$ & $0.0 \%$ \\
\hline 2010 & $17.1 \%$ & $18.2 \%$ & $-1.1 \%$ \\
\hline 2011 & $16.7 \%$ & $16.8 \%$ & $0.0 \%$ \\
\hline 2012 & $16.9 \%$ & $16.9 \%$ & $0.0 \%$ \\
\hline 2013 & $17.4 \%$ & $17.3 \%$ & $0.0 \%$ \\
\hline 2014 & $17.9 \%$ & $18.1 \%$ & $-0.2 \%$ \\
\hline 2015 & $17.9 \%$ & $19.4 \%$ & $-1.6 \%$ \\
\hline 2016 & $19.5 \%$ & $20.0 \%$ & $-0.5 \%$ \\
\hline
\end{tabular}

Fonte: STN, BCB.

\section{Análise dos Resultados}

A tabela no anexo, ao final deste artigo, apresenta a evolução ano a ano da despesa primária e de todos os seus componentes em percentual do PIB corrente. Essas estimativas revelam que a despesa primária da União passou de 12,7\% do PIB, em 1986, para 19,5\% do PIB em 2016 - um incremento de 6,8 p.p. do PIB, ou 0,34 p.p. ao ano no período (Gráfico 1). 
Do ponto de vista dinâmico, a despesa caiu de forma substantiva entre 1987 e 1992, saindo de 13\% do PIB para 10,6\% do PIB. Após esse período, a despesa começa a subir de forma bastante acelerada em 1993 e 1994, atingindo $14 \%$ do PIB, biênio no qual devolveu todo o ajuste realizado anteriormente.

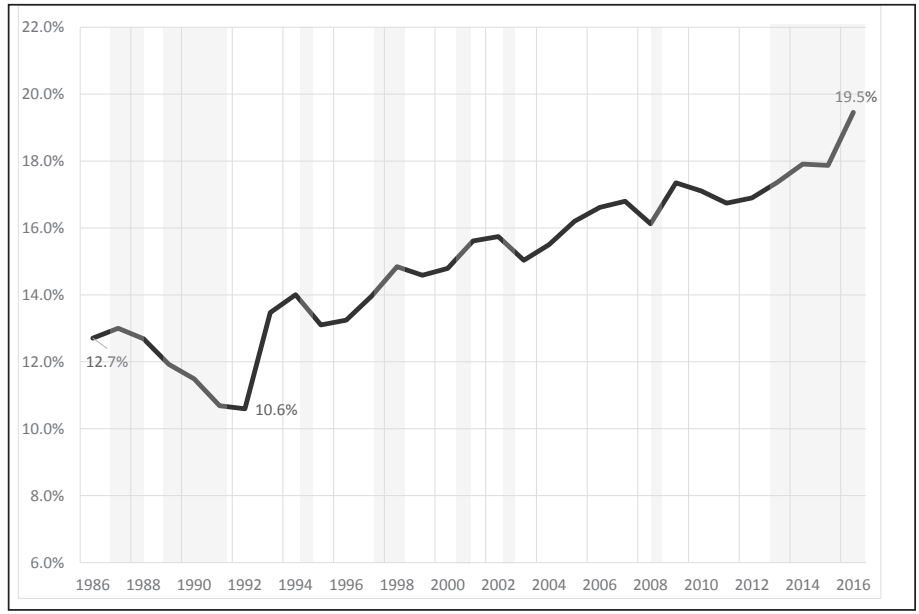

Gráfico 1 - Evolução das despesas primárias (\% do PIB)

* Áreas hachuradas em cinza: recessões datadas pelo CODACE/FGV.

Após a estabilização da inflação, a despesa primária caiu para 13,1\% do PIB em 1995. A partir daí, cresceu de forma relativamente ininterrupta, até chegar em 19,5\% do PIB em 2016. As exceções nessa trajetória foram as quedas em 2003 (resultado de um forte ajuste fiscal) e em 2008 (quando PIB apresentou forte crescimento real).

As áreas sombreadas representam os períodos em que o país entrou em recessão tal como datado pelo CODACE/FGV (2015). Fica evidente que não há um claro padrão cíclico de comportamento das despesas. Nas recessões observadas no final dos anos 1980 e início dos anos 1990, o gasto público caiu de forma expressiva. ${ }^{20}$

${ }^{20}$ Após o Plano Real, ainda nos anos 1990, os curtos períodos recessivos não parecem ter impactado a evolução das despesas na mesma direção. Em alguns anos observou-se elevação da despesa, como em 1998, ao passo que, em outros casos, houve queda (como em 1995). Nos anos 2000, essa falta de correlação também ocorre. Na breve recessão de 2001, a despesa aumentou, enquanto na recessão de 2004, a despesa caiu. Em 2008, na crise financeira internacional, o governo adotou uma política expansionista que ficou bastante conhecida e a despesa cresceu no período. Por fim, durante a recessão 
É importante constatar que uma parte do ajuste ocorrido no início dos anos 1990 está relacionado à aceleração da taxa de inflação que corroía o valor da despesa quando o governo atrasava os pagamentos. Esse efeito é conhecido como efeito Tanzi (1994). ${ }^{21}$ Assim, utilizar o início dos anos 1990 como ponto de partida para a discussão sobre o crescimento da despesa parece exagerar o efeito da Constituição Federal de 1988.

Uma crítica recorrente a essa análise preliminar dos dados e da sua relação com o ciclo econômico é que em períodos de baixo crescimento ou mesmo de crescimento negativo, a razão entre a despesa e o PIB tende a aumentar pelo comportamento do denominador, o que pode distorcer a análise levando a conclusões equivocadas sobre o comportamento cíclico da política fiscal. Para avaliar o efeito desse tipo de crítica, foi analisado o comportamento da despesa em relação ao PIB potencial. ${ }^{22}$

O Gráfico 2 apresenta a comparação entre a série original e a nova série em proporção do PIB potencial. A diferença mais marcante entre as variáveis está na leitura do comportamento da despesa na recessão que foi iniciada em 2014. De acordo com os dados referenciados no PIB potencial, o ano de 2015 foi um ano de queda de despesas primárias, com um ajuste fiscal ligeiramente superior àquele observado em 2003. Em 2003, a despesa primária caiu 0,8 p.p. do PIB potencial enquanto no ano de 2015 a queda foi de 0,9 p.p. do PIB potencial.

Isso, contudo, não altera em praticamente nada o diagnóstico sobre o comportamento da despesa em uma perspectiva de longo prazo, qual seja: (i) a despesa primária apresenta uma tendência quase ininterrupta de crescimento estrutural em percentual do PIB desde 1992 e; (ii) não existe um padrão cíclico bem definido do gasto do governo central.

iniciada em 2014, a despesa também cresceu. Para uma análise da política fiscal nos ciclos recessivos de 2003, 2008 e 2014, ver Pires (2017).

${ }^{21}$ A análise de Tanzi (1994) se referia ao efeito sobre as receitas provocado pela inflação. Ao longo do início dos anos 1990 também era comum se referir a esse efeito para tratar das despesas primárias.

${ }^{22}$ O PIB potencial nominal foi obtido a partir da aplicação da estimativa de hiato de produto médio anual da IFI/Senado, cuja metodologia é apresentada em Orair e Baciotti (2018) ao PIB nominal efetivo a preços de mercado. Como a série estimada pela IFI está disponível somente a partir de 1996, o hiato no período 1986-1995 foi estimado a partir de um modelo de séries de tempo relacionando o hiato estimado pela IFI entre 1996 e 2017 com o Nível de Utilização da Capacidade Instalada (NUCI) da indústria de transformação apurado pela FGV e com a variação do PIB per capita em volume. Como essas duas variáveis explicativas dispõem de dados trimestrais desde 1980, foi possível obter uma estimativa econométrica do hiato entre 1980 e 1995. 


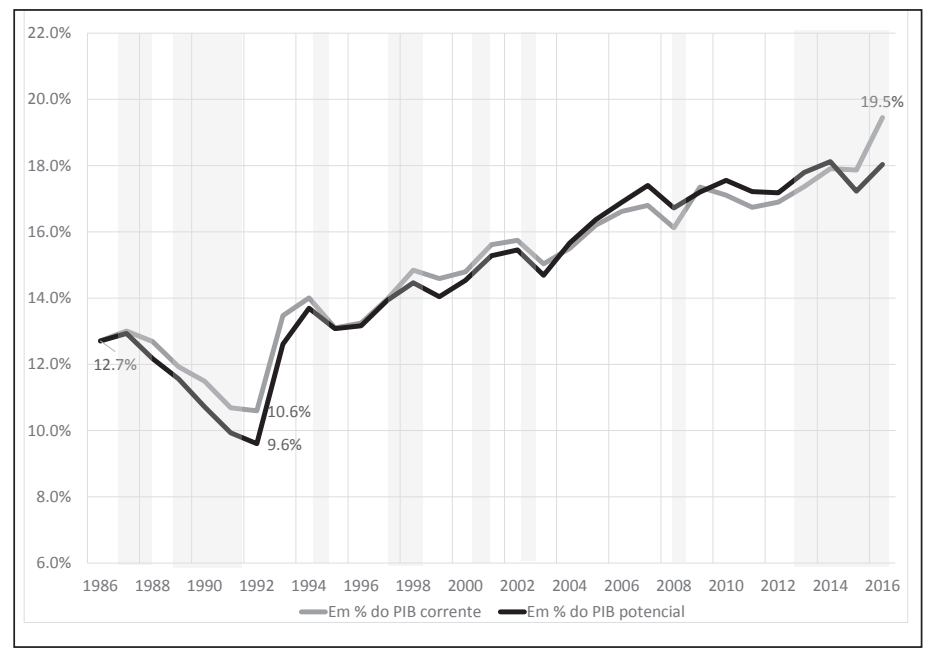

Gráfico 2 - Evolução das despesas primárias (\% do PIB potencial)

* Áreas hachuradas em cinza: recessões datadas pelo CODACE/FGV.

A partir desses dados, é possível fazer uma periodização do comportamento da política fiscal associado ao comportamento da despesa durante períodos de cinco anos, o que reduz a influência de ciclos políticos e efeitos cíclicos que possam afetar a despesa (Tabela 3). Os dados, em percentual do PIB potencial, indicam que houve uma expressiva redução da despesa no final dos anos 1980 concentrado em subsídios e custeio.

Essa queda nos subsídios ocorre por conta da reversão dos estímulos dados ao setor produtivo para estimular as exportações na esteira da crise do balanço de pagamentos do início dos anos 1980. O quinquênio seguinte reverteu esse processo, com crescimento expressivo em pessoal e previdência. $\mathrm{O}$ crescimento em previdência está relacionado ao processo de regulamentação dos dispositivos da $\mathrm{CF} / 88$ que se deu nesse período, enquanto o crescimento das despesas com pessoal ocorreu durante o Governo Itamar, com incorporação de servidores e uma nova política salarial.

Nos 10 anos seguintes, entre 1996 e 2006, a despesa cresceu de maneira mais uniforme. A diferença mais marcante está na composição já que o crescimento da despesa com previdência na segunda metade desse período (entre 2001 e 2006) foi expressivo enquanto o custeio foi o principal responsável pelo crescimento da despesa no quinquênio anterior (entre 1996 
e 2001), tendo havido alguma recomposição a partir da criação de algumas que políticas cujo efeito será examinado mais à frente.

No período entre 2006-2011, a despesa primária cresceu 0,32 p.p. do PIB potencial, com destaque para os benefícios assistenciais e as despesas com custeio, principalmente investimentos. No quinquênio entre 2011 e 2016, a despesa cresceu 0,82 p.p. do PIB potencial, com maior destaque para as despesas previdenciárias.

Dessa forma, os componentes da despesa mais sensibilizados em períodos de ajuste fiscal foram os subsídios e as despesas de custeio (que incluem investimento) no início do período de análise, enquanto que as despesas com pessoal começam a se contrair desde a segunda metade dos anos 1990. Novamente, as despesas com previdência e assistência são os itens que geram essa tendência de crescimento estrutural da despesa.

A Tabela no anexo ao final deste artigo decompõe a trajetória da despesa primária entre todos os seus componentes. As estatísticas de investimento só estão disponíveis a partir de 1995. Assim, é importante averiguar como a evolução do custeio se deu nesse período. Os investimentos públicos seguem uma trajetória de recomposição a partir do forte ajuste ocorrido em 2003, que levou essa rubrica a 0,3\% do PIB, o menor valor da série histórica. Dessa forma, o crescimento do custeio entre 2003 e 2010 ocorreu basicamente por elevação do investimento público. A partir de 2011, o que se verifica é a reversão desse processo com uma queda na margem dos investimentos públicos.

Tabela 3 - Variação da despesa (Em p.p. do PIB potencial)

\begin{tabular}{|r|r|r|r|r|r|r|}
\hline & Pessoal & Previdência & $\begin{array}{l}\text { RMV, LOAS, BPC } \\
\text { e Seguro D. }\end{array}$ & Subsídios & Custeio & \multicolumn{1}{c|}{ Total } \\
\hline $1991 / 1986$ & 0.66 & -0.22 & 0.23 & -1.10 & -2.34 & -2.78 \\
\hline $1996 / 1991$ & 1.61 & 1.58 & 0.11 & 0.03 & -0.11 & 3.23 \\
\hline $2001 / 1996$ & -0.05 & 0.90 & 0.05 & 0.12 & 1.09 & 2.11 \\
\hline $2006 / 2001$ & -0.20 & 1.39 & 0.23 & 0.06 & 0.14 & 1.62 \\
\hline $2011 / 2006$ & -0.24 & -0.37 & 0.23 & -0.13 & 0.83 & 0.32 \\
\hline $2016 / 2011$ & -0.45 & 0.90 & 0.12 & 0.15 & 0.10 & 0.82 \\
\hline
\end{tabular}

Como a trajetória de crescimento da despesa primária está muito relacionada ao crescimento da despesa com previdência e demais benefícios assistenciais, é importante observar a trajetória da despesa primária excluindo a previdência social e os outros benefícios sociais. 
O Gráfico 3 apresenta a evolução da despesa primária excluindo os benefícios previdenciários e o total de transferências de renda (que inclui o BPC, RMV, seguro desemprego e EPU). Os dados indicam que o crescimento da despesa foi bem mais moderado. Considerando, por exemplo, as despesas exclusive a previdência, o crescimento foi de 1,1 p.p. do PIB entre 1986 e 2016. Excluindo todas as transferências de renda, o crescimento foi de apenas 0,2 p.p. do PIB. Dessa forma, os dados agregados mostram a importância da previdência e dos benefícios assistenciais no crescimento estrutural da despesa primária.

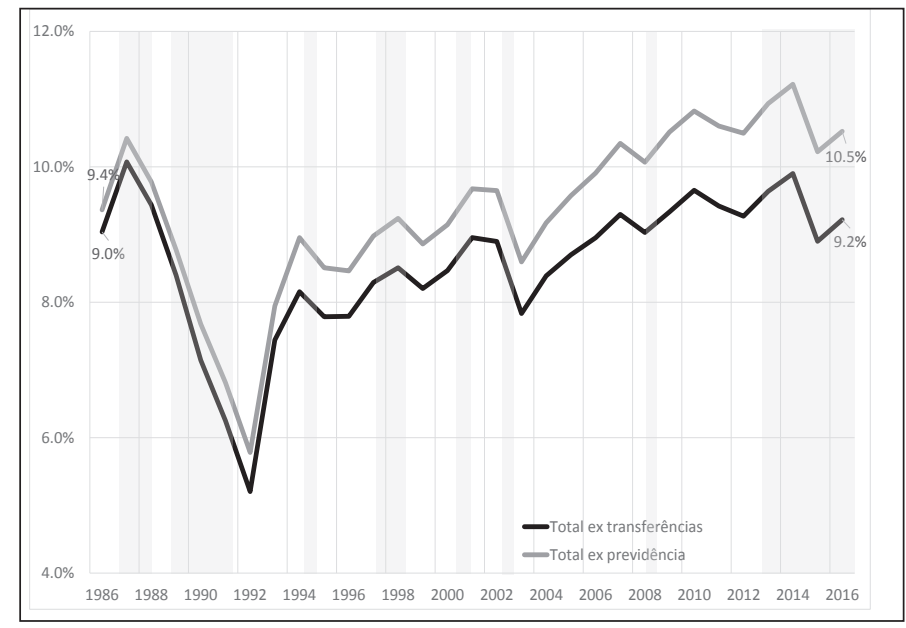

Gráfico 3 - Evolução da despesa primária excluindo benefícios sociais (\% do PIB potencial)

* Áreas hachuradas em cinza: recessões datadas pelo CODACE/FGV.

\section{Análise dos Determinantes da Despesa Primária}

O gasto primário do governo central em 1988 - ano da promulgação da CF/88 - equivaleu a $12,7 \%$ do PIB, nível semelhante ao observado na média de 1986-1987 (12,9\%). Em 2016, levando em conta os ajustes metodológicos realizados descritos nas seções anteriores, a despesa primária chegou a $19,5 \%$. 
Além disso, é pertinente também descontar a diferença entre as posições cíclicas do PIB brasileiro nesses dois anos específicos. ${ }^{23}$ Esse impacto é de cerca de 1,1 p.p., levando em conta apenas o efeito denominador nesse cálculo (ou seja, ignorando eventuais impactos do ciclo sobre algumas despesas, como o gasto com seguro-desemprego).

Desse modo, a despesa primária do governo central em percentual do PIB potencial equivalia a $12,2 \%$ do PIB em 1988, chegando a $18,0 \%$ em 2016 , resultando em um incremento de 5,7 pontos percentuais do PIB potencial ao longo desses quase 30 anos.

Nesse contexto, o objetivo desta seção é decompor a evolução do gasto entre 1988 e 2016 nos seus principais determinantes, buscando distinguir entre os efeitos diretamente originados pela $\mathrm{CF} / 88$ e aqueles decorrentes de outros fatores. Em nosso entendimento, esse é o primeiro estudo que tenta avaliar essa questão. ${ }^{24}$

Como o gasto previdenciário foi o item de despesa que mais cresceu no período, ${ }^{25}$ é importante tentar decompor mais cuidadosamente seus principais condicionantes. O primeiro diz respeito ao impacto quantitativo, ilustrado no gráfico a seguir.

${ }^{23} \mathrm{Em} 1988$, o hiato do produto era pouco negativo (cerca de -1,5 p.p.), ao passo que em 2016 ele foi negativo em quase 7 pontos percentuais (levando em conta médias anuais).

${ }^{24}$ Almeida, Lisboa \& Pessoa (2015) apenas identificaram que boa parte do aumento da despesa entre 1991 e 2014 se deveu ao chamado gasto social - sem, no entanto, avaliar se a dinâmica desse e dos demais gastos estavam diretamente relacionadas a dispositivos constitucionais. Além disso, ao utilizarem o ano de 1991 como base, a análise fica relativamente distorcida, já que a forte aceleração da inflação entre o final dos anos 80 e o começo dos anos 90 , bem como o ajuste fiscal realizado no período, deprimiu a base da despesa primária nesse ano.

25 Como indicado anteriormente, essa despesa passou de 2,5\% do PIB em 1988, para 8,1\% em 2016, somando benefícios previdenciários e assistenciais. Ou seja: mais do que triplicou, em porcentagem do PIB. 


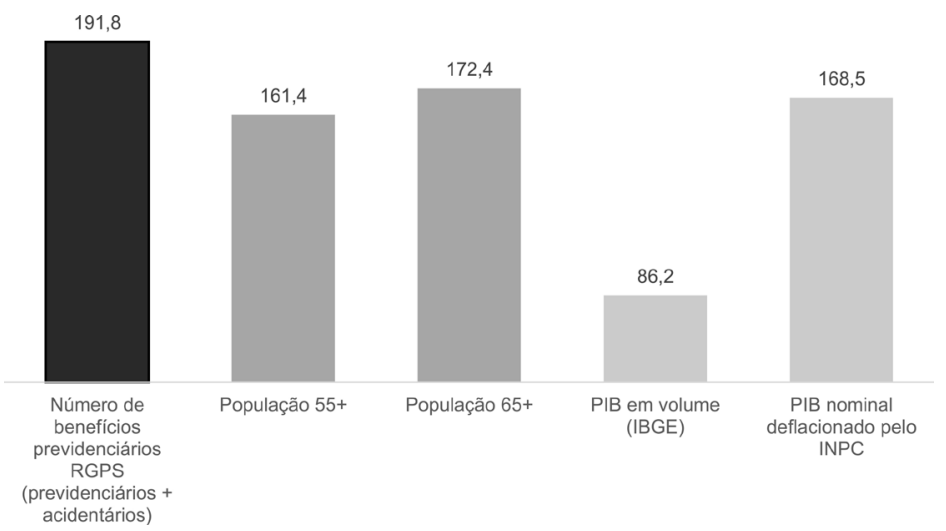

Gráfico 4 - Indicadores selecionados: variação \% acumulada 2016 vs 1988 Fonte: IBGE, IPEA e MPS.

Como pode ser notado, houve um crescimento de 192\% do número de benefícios previdenciários no âmbito do RGPS entre 1988 e 2016. Tratase de uma variação bastante expressiva, mas que não ficou tão distante do crescimento sugerido por alguns indicadores demográficos. ${ }^{26}$

Quando se compara esse crescimento do número de benefícios previdenciários com o crescimento real do PIB brasileiro descontada a inflação do INPC (que é aquela que serve de referência para os reajustes salariais e dos valores dos benefícios), nota-se que eles não foram tão discrepantes, ${ }^{27}$ o que significa dizer que boa parte do aumento do gasto previdenciário decorreu de um aumento relevante do valor médio dos benefícios.

Um aumento médio desses benefícios pode acontecer por vários canais, como um aumento dos salários médios praticados na economia (que servem de referência para o cálculo do benefício) e pelo aumento do valor do piso previdenciário.

${ }^{26}$ Valendo lembrar que as aposentadorias por tempo de contribuição, no Brasil, têm ocorrido com uma idade entre 53 e 55 anos para mulheres e homens, ao passo que nas aposentadorias por idade, os limites mínimos são de 60 e 65 anos, respectivamente.

$27 \mathrm{O}$ crescimento do PIB em volume reportado oficialmente foi de praticamente metade da variação real do PIB nominal descontada a inflação do INPC. Isso se explica pelo fato de que tem sido sistemática, no Brasil, uma divergência positiva entre a variação do deflator do PIB e a variação da inflação média captada pelo IPCA/INPC. 
A CF/88 introduziu a vinculação do piso previdenciário e dos benefícios assistenciais ao salário-mínimo nacional. Por outro lado, a Carta Magna apenas estabeleceu, em seu Artigo $7^{\circ}$, Inciso IV, que o salário-mínimo nacional deveria sofrer "(...) reajustes periódicos que lhe preservem o poder aquisitivo".

Quando se comparam os anos de 1988 e 2016, constata-se que houve um incremento de $62 \%$ do valor real do salário-mínimo nacional (de R \$ 560 para $R \$ 900$ em termos de médias anuais, a preços de agosto de 2017 pelo INPC/IBGE). A política de reajustes reais relevantes do salário-mínimo nacional ocorreu em todos os governos pós estabilização. ${ }^{28}$

Desse modo, a política de reajuste reais do salário-mínimo nacional praticada desde 1995 explica uma parcela importante do aumento do valor médio dos benefícios previdenciários observado entre 1988 e 2016. Quando se levam em conta também os efeitos sobre os gastos com benefícios assistenciais (para idosos e deficientes físicos), com o abono salarial e com o seguro-desemprego, estima-se que, do aumento de 5,7 pontos percentuais do gasto primário do governo central na comparação 1988-2016, cerca de 1,9 p.p. ${ }^{29}$ (ou $35 \%$ ) adveio da política de reajustes reais do salário-mínimo efetivamente praticada nesse ínterim. ${ }^{30}$

${ }^{28}$ Entre 1995 e 2007, a magnitude dos reajustes reais do salário-mínimo era decidida de forma totalmente discricionária, no âmbito das negociações entre o Executivo e o Legislativo, envolvendo a preparação dos orçamentos anuais. Entre 2008 e 2010 adotou-se, informalmente, uma regra que determinava que o reajuste nominal dessa variável em um determinado ano $\mathrm{T}$ seria equivalente ao acúmulo da inflação medida pelo INPC efetivamente observada em T-1 com o crescimento real do PIB verificado em T-2 (caso este fosse positivo). Junto com isso, houve uma transição gradativa da data do reajuste, que tradicionalmente ocorria nos meses de abril ou maio, passando para março em 2008, fevereiro em 2009 e janeiro em 2010. Essa regra informal foi transformada em uma Lei Ordinária a partir de 2011, a qual expirou em 2015, tendo sido reeditada, vigorando até 2019.

${ }^{29}$ Para estimar esse impacto, foi considerada a premissa de que, a partir de 2006, o salário-mínimo nacional teria sido reajustado utilizando somente a inflação passada apurada pelo INPC. Esse ano foi escolhido pois o valor real do salário-mínimo era muito próximo daquele observado em 1988. Entre 1989 e 1994, o salário-mínimo real perdeu 31,5\% de seu valor, por conta da aceleração inflacionária observada durante boa parte desse período. Entre 1995 e 2005, os reajustes reais do salário-mínimo foram suficientes para recompor o nível observado em 1988. Na sequência, foram utilizados dados, ano a ano, do número de benefícios com valor de até 1 salário-mínimo, admitindo a mesma quantidade efetivamente observada entre 2006 e 2016, mas com o valor médio alterado para o salário-mínimo contrafactual. Esse procedimento gerou uma despesa previdenciária 1,6 p.p. do PIB menor em 2016. No caso do seguro-desemprego e do abono salarial, foi aplicada um fator proporcional (salário-mínimo contrafactual sobre salário-mínimo observado), ano a ano, nos valores efetivamente gastos, gerando um impacto estimado de 0,3 p.p. do PIB em 2016 (que pode estar superestimado, na medida em que nem todas as faixas de seguro-desemprego acompanham os reajustes do salário-mínimo).

${ }^{30}$ Uma questão relevante é até que ponto o efeito do reajuste real do salário mínimo não seria um efeito constitucional também. Em nossa avaliação, a Constituição definiu apenas um piso real para o valor dessa variável, ao determinar tão somente que ela tenha seu poder de compra preservado ao longo do tempo. Qualquer reajuste real ex-ante situado entre $+0,01 \%$ e infinito no acumulado de 1988-2016 
Outro condicionante importante da evolução do gasto primário do governo central entre 1988-2016 foi a concessão de reajustes reais acumulados de quase $16 \%$ para os benefícios previdenciários com valor superior a um salário-mínimo entre 1995 e 2010, sobretudo em 1995-2002 (+10,3\%). Isso refletiu, claramente, decisões políticas de alguns governos, não tendo nenhuma relação com a Constituição. $\mathrm{O}$ impacto estimado sobre o gasto primário do governo central é da ordem de $+0,5$ p.p. do PIB em 2016 . $^{31}$

Também há uma miríade de outros gastos criados ao longo de 1988-2016, sobretudo a partir de 1996, somando ao todo 1,45\% do PIB em 2016, que podem ser classificados como políticas dos vários governos que comandaram o país ao longo desse período, não estando diretamente ligados às determinações constitucionais (Gráfico 5).

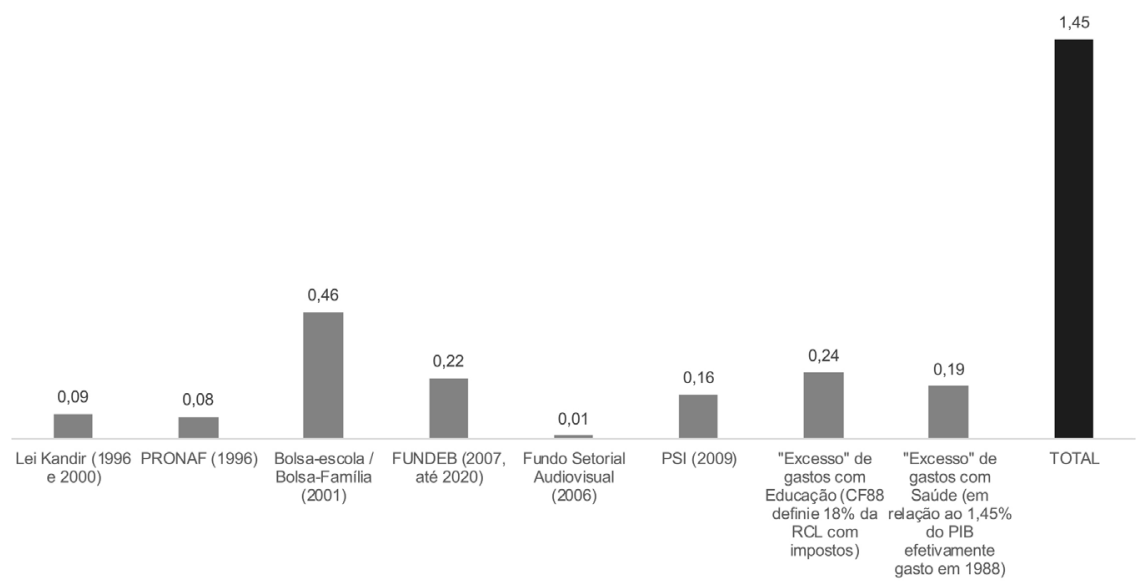

Gráfico 5 - Despesa Primária Criada depois da CF/88 (\% do PIB)

* Valores em 2016, em \% do PIB. Data de criação da despesa entre parênteses.

Fonte: Tesouro Nacional.

atenderia às determinações constitucionais, mas com impactos sobre os gastos, considerando esses exemplos extremos, completamente diferentes. No final das contas, a conclusão é que seria possível ter um efeito diferente e o mandato Constitucional seria cumprido da mesma forma.

31 Esse impacto foi estimado descontando-se esse percentual do valor médio dos benefícios para aqueles que ganham acima de 1 salário-mínimo em 2016. 
Esses gastos foram mapeados, um a um, a partir de um cruzamento das rubricas de gastos efetivamente observadas em 2016 com o histórico no momento de sua criação. É importante assinalar, a esse respeito, que a $\mathrm{CF} / 88$ não criou nenhum tipo de vinculação para os gastos com saúde. Isso foi acontecer somente em 2000, com a promulgação da Emenda Constitucional $\mathrm{n}^{\circ} 29$, posteriormente alterada em 2015 (EC $\mathrm{n}^{\circ} 86$ ) e em 2016 (pela EC n ${ }^{\circ}$ 95, que criou o teto de gastos para o governo central e definiu um piso real de gastos para saúde e educação). Desse modo, o gasto adicional com saúde apontado no gráfico acima, foi obtido a partir da comparação do gasto efetivo com essa função em 2016 versus $1988 .{ }^{32}$ No caso do gasto com educação, comparamos o gasto efetivamente observado em 2016 vs o mínimo definido pela Constituição.

Com base em tudo que foi exposto, o Gráfico 6 apresenta uma decomposição resumida da evolução do gasto primário recorrente do governo central na comparação entre 1988 e 2016, em percentual do PIB potencial.

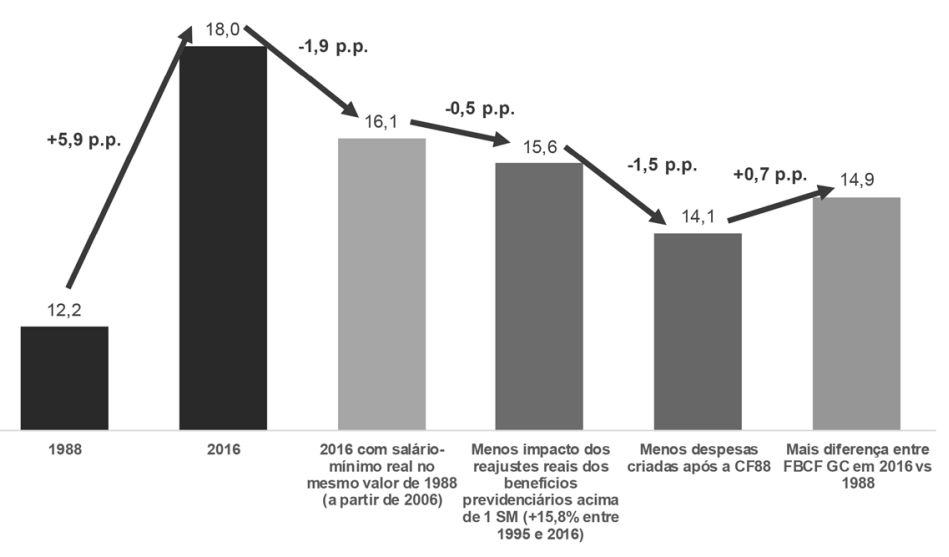

Gráfico 6 - Decomposição dos condicionantes da Despesa Primária do Governo Central: 1988 vs 2016 (\% do PIB potencial)

Resumindo, há na comparação entre os anos de 1988 e 2016, pelo menos 2,0 pontos percentuais do aumento da despesa nesse ínterim decorrentes de reajustes dos benefícios previdenciários acima de 1 salário-mínimo e gastos correlatos criados após a Constituição de 1988, que não podem ser

32 Reconhecemos que é possível argumentar que uma vezaprovada a Emenda Constitucional no 29 essa despesa passou a ser determinada pela CF. Nesse caso, esse valor deve ser subtraído do total de 1,7\% do PIB. 
atribuídos diretamente às determinações da Carta Magna. Isso corresponde a $34 \%$ do aumento da despesa observada nesse período. Há, ainda, cerca de $32 \%$ do aumento desse gasto associado à política de reajustes efetivamente praticada nesse período do salário-mínimo nacional - os quais, como apontamos, não podem ser diretamente associados às determinações constitucionais.

Interessante notar, ainda, que o governo central investiu 1,2\% do PIB em 1988 , percentual que recuou para $0,4 \%$ em $2016^{33}$ (valendo lembrar que essa é a principal rubrica de despesa sem controle de fluxo, discricionária). Desse modo, quando se excluem os fatores mencionados acima e se considera esse diferencial entre os gastos de investimento, é possível inferir que a Constituição "cidadã" e a dinâmica demográfica efetivamente observada (ver Gráfico 4) poderiam ser responsabilizados por cerca de 2,7 p.p. (14,9\% vs $12,2 \%$ do PIB) do aumento do gasto primário do governo central entre 1988 e 2016 (ou 46\% do aumento total de 5,9 p.p. do gasto nesse ínterim).

\section{Considerações Finais}

O principal objetivo deste artigo foi apresentar estimativas das despesas primárias para o Governo Federal iniciadas em 1986 - agregando 11 anos às séries históricas atualmente disponíveis oficialmente e estudar os condicionantes do aumento da despesa primária no período.

A partir desse conjunto de informações mais amplo, é possível aprimorar a compreensão acerca da dinâmica da despesa, de seu processo de formação, sobretudo no que toca ao impacto da promulgação da CF/88 sobre a evolução dos gastos públicos desde então, às políticas criadas e que também impactaram sua evolução e sua composição.

Os resultados indicam que o crescimento estrutural da despesa primária federal no Brasil nesse período pós CF 88 está muito associado à previdência social. Os ajustes fiscais que foram implementados permitiram uma acomodação momentânea dessa despesa em circunstâncias bem específicas (como foram os casos em 1999, 2003 e 2015).

${ }^{33}$ Segundo estimativas de Orair (2016). 
Por outro lado, os dados apontam que houve uma forte redução da despesa em porcentagem do PIB em 1989-92 (cerca de 3 p.p. do PIB abaixo da observada em 1988), refletindo sobretudo a expressiva aceleração da inflação ao longo desse período e um processo de ajuste estrutural que conduziu a transição de um estado desenvolvimentista para um estado de bem-estar social.

Desse modo, análises que tomam o início dos anos 90 como ponto de partida (Almeida, Lisboa \& Pessoa 2015) tendem a exagerar, em alguma medida, a magnitude do crescimento do gasto primário até o momento atual. Ao mesmo tempo, nossos resultados relativizam a importância do efeito cremalheira e dão mais importância ao crescimento da despesa obrigatória, seja devido aos fundamentos presentes na $\mathrm{CF} / 88$, seja em função das várias decisões tomadas pelos vários governos que buscaram atender as novas demandas sociais que surgiram no período.

Por fim, foi apresentada uma decomposição dos condicionantes das despesas, buscando separar suas origens entre fatores constitucionais e aqueles não relacionados diretamente à $\mathrm{CF} / 88$. O exercício mostrou que sem os componentes não constitucionais, a despesa primária poderia estar 3,2 p.p. do PIB menor em 2016 comparativamente ao dado efetivamente observado (admitindo, em 2016, o mesmo nível de investimento de 1988). As estimativas mostram, ainda, que a CF/88 contribuiu com 2,7 p.p. do PIB.

Essa constatação não deve ser utilizada para diminuir a relevância do fenômeno do crescimento da despesa primária no Brasil, em particular o papel da CF/88, tampouco para reduzir a importância das despesas que foram criadas nesse período, mas coloca em uma perspectiva mais adequada o debate sobre onde e como a despesa deve ser ajustada, dá a magnitude desse desafio e mostra que esse processo é mais complexo do que normalmente apresentado pela literatura. 


\section{Referências}

Almeida Jr, M.; Lisboa, M.R.; Pessoa, S. 2015. "O ajuste inevitável”. Artigo publicado na Folha de São Paulo em 19/07/2015.

Austin, A. 2015. "The debt limit: history and recent increases". CRS report.

Bonomo, M., Brito, R. \& Martins, B. 2015. "Macroeconomic and financial consequences of the post crisis government driven credit expansion in Brazil”. BID working paper 551.

Cahuc, P. \& Carcillo, S. 2012. "Can public wages bills be reduced?" NBER working paper 17.881.

Crivelli, E., Gupta, S., Mulas-Granados, C. \& Correa-Caro, C. 2016. "Fragmented Politics and Public Debt". IMF Working paper, no. 16.

Giambiagi, F. e Barbosa, F. 1995. "O ajuste fiscal de 1990-93: uma análise retrospectiva". Revista Brasileira de Economia 49(3): 521-43.

Giambiagi, F. 1997. “A crise fiscal da União: O que aconteceu recentemente?” Revista de Economia Política 65(1): 60-79.

Giambiagi, F. e Além, A. C. 2008. "Finanças Públicas". Editora Campus.

Orair, R. e Baciotti, R. 2018. "Hiato do produto na economia brasileira: estimativas da IFI pela metodologia de função de produção". Estudo Especial n 4, Instituição Fiscal Independente (IFI) - Senado Federal.

Orair, R. e Gobetti. 2016. "Resultado Primário e contabilidade criativa: reconstruindo as estatísticas fiscais 'acima da linha' do governo geral”. Texto para Discussão IPEA, no 2.288.

Orair, R. 2016. "Investimento público no Brasil: trajetória e relações com o regime fiscal". Texto para Discussão IPEA, no 2.215 .

Persson, T. e Tabellini, G. 2002. "Political Economics: explaining economic policy". Zeuthen Lectures, MIT Press.

Pires, M. 2017. "Política fiscal e ciclos econômicos: Teoria e experiência recente". Editora Elsevier.

Rezende, F. 2001. "Finanças Públicas". Editora Atlas.

Rezende, F., Araújo, E. e Oliveira, F. 2006. “O dilema fiscal. Remendar ou reformar?” Editora FGV.

Receita Federal do Brasil. 2016. "Carga tributária no Brasil 2015. Análise por tributos e bases de incidência". Ministério da Fazenda, setembro.

Schaechter, A., Kinda, T., Budina, N., Weber, A. 2012. "Fiscal rules in response to the crisis - Toward the next generation rules: A new dataset". IMF working paper, no 187.

SPE. 2016. "Monitor de Política Fiscal: Resultado Estrutural”. Ministério da Fazenda, maio.

Tanzi, O. 1994. “The individual income tax and economic growth”. John Hopkins University Press. 


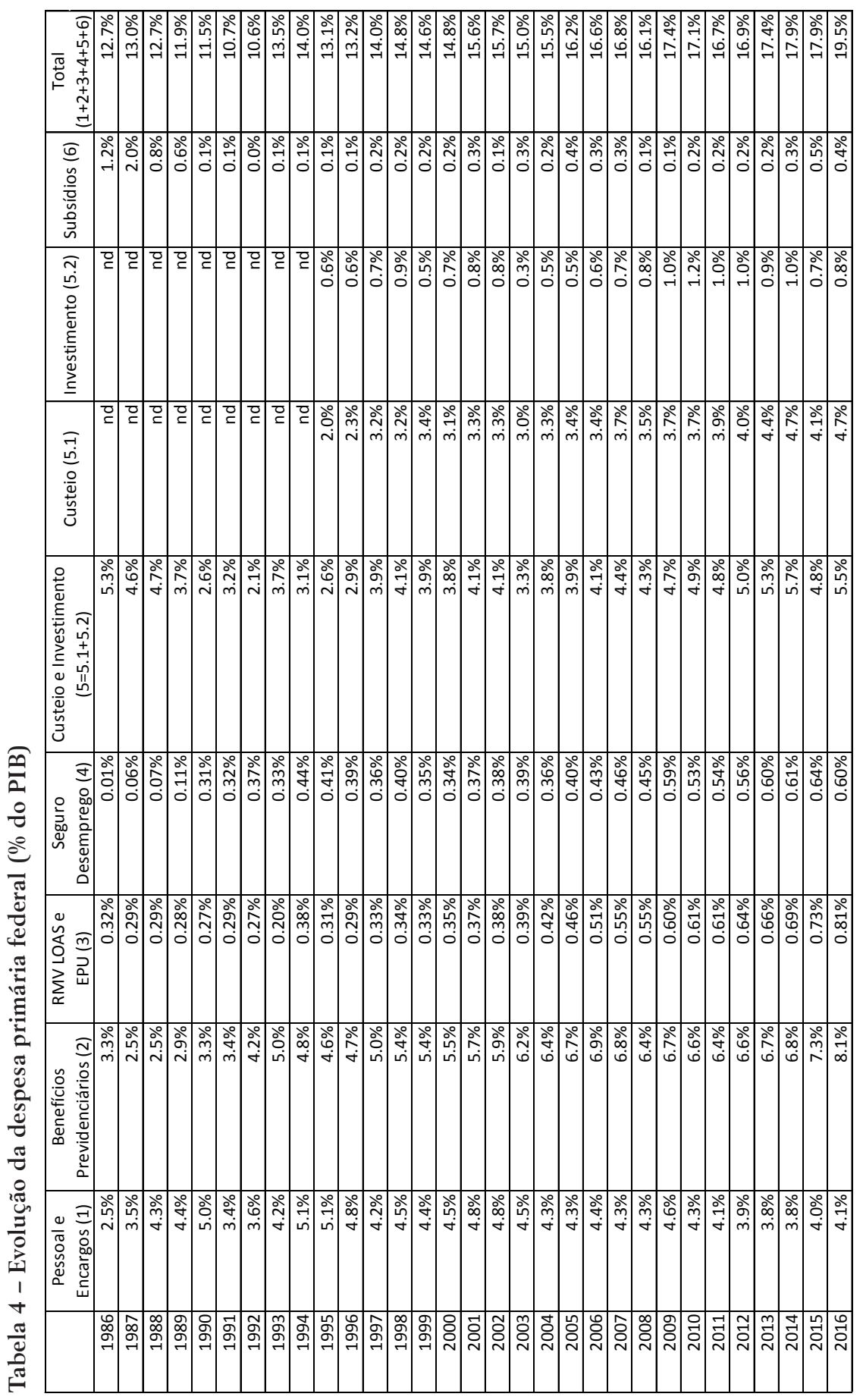




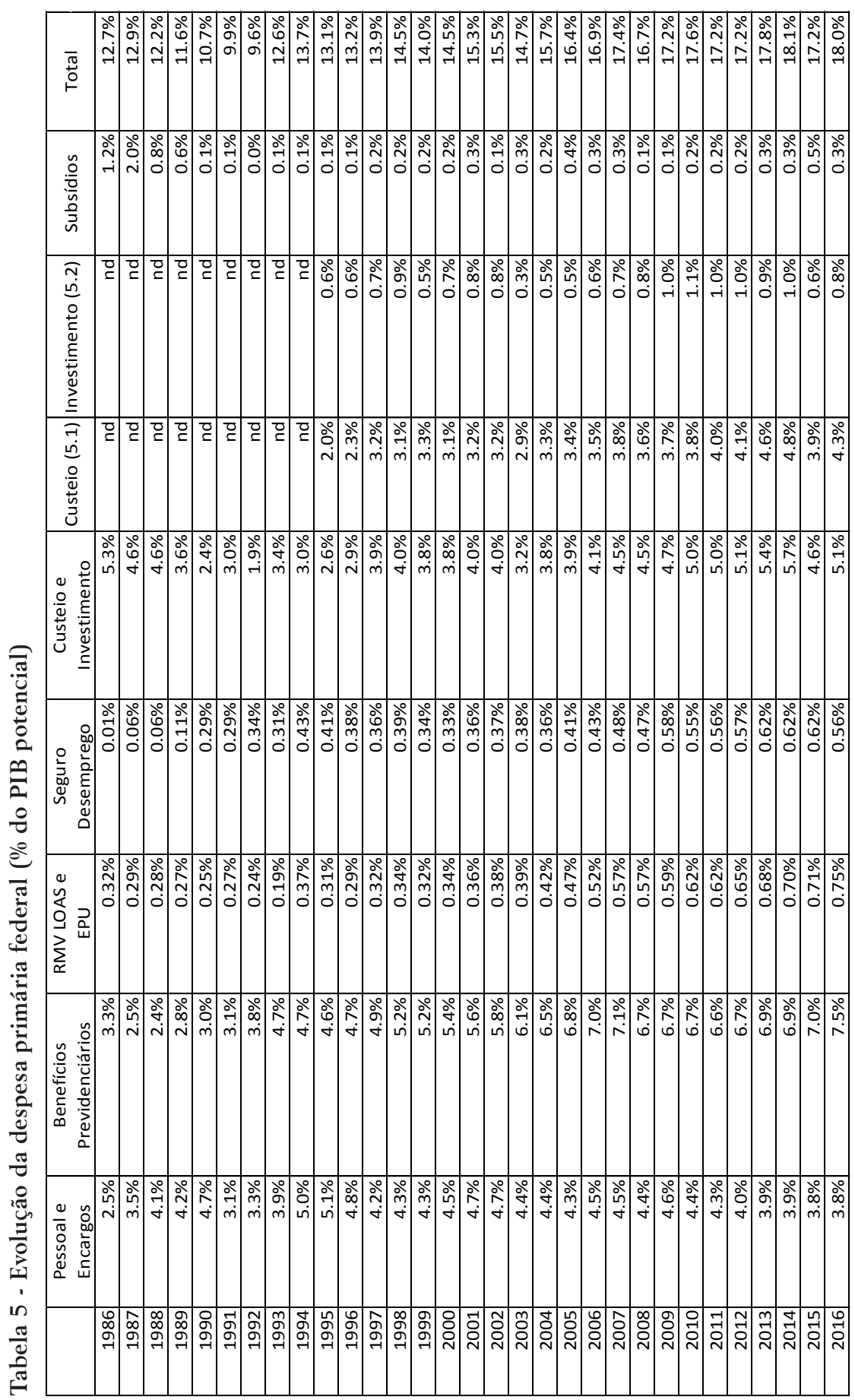

